\title{
A RELAÇÃO TEORIA E PRÁTICA: INVESTGANDO AS COMPREENSÕES DE PROFESSORES QUE ATUAM NA EDUCAÇÃO PROFISSIONAL
}

\author{
MORAIS, J. de M.*; SOUZA, P.; COSTA, T.; \\ Instituto Federal de Educação, Ciência e Tecnologia do Rio Grande de Norte \\ jacy medeiros@hotmail.com, costatemilson@gmail.com*
}

Artigo submetido em março/2017 e aceito em maio/2017

DOI: $10.15628 /$ rbept.2017.5720

\section{RESUMO}

A relação teoria e prática é uma problemática que se apresenta em todo processo formativo, suas formas de articulação expressam posições político-pedagógicas em que a ação educativa é desenvolvida. Na educação profissional a integração da teoria com a prática é dimensão basilar quando se almeja um ensino de formação integral dos sujeitos. Compreender a relação teoria e prática no trabalho de professores de formação geral que atuam na educação profissional consiste no objetivo desta pesquisa, que foi desenvolvida de acordo com a metodologia da pesquisa qualitativa, obtendo os dados a partir de uma entrevista semi-estruturada com 04 professores que atuam em duas escolas da rede privada de ensino profissional da cidade de Natal/RN.
\end{abstract}

Para reflexão sobre as compreensões dos professores, autores como Candau (2013), Pimenta (2012), Moura (2007), Machado (2013), Vázquez (2011) e Araújo e Rodrigues (2011), nos ajudaram a tecer as discussões e análises. Sendo possível entender que a relação teoria e prática é indispensável no desenvolvimento de uma formação para educação professional. Suas formas de articulação acontecem, principalmente, pelas visões dicotômica e de unidade. A partir da compreensão dos professores foi possível perceber que há uma prevalência da visão dicotômica da relação teoria e prática na atuação docente da formação técnica professional.

PALAVRAS-CHAVE: Relação teoria e prática. Professores. Educação Profissional.

\section{RELATION THEORY AND PRACTICE: INVESTIGATING THE TEACHER'S UNDERSTANDINGS ACTING IN PROFESSIONAL EDUCATION}

\begin{abstract}
The relationship between theory and practice is a problem which is present in every training process, its articulation's paths express political-pedagogical positions where the educational activity is developed. In professional education the integration between theory and practice is fundamental dimension when you aim at teaching comprehensive training of the subjects. Understanding the relationship between theory and practice in the work of general education teachers who work in education is the purpose of this research, which was developed according to the qualitative research methodology, obtaining data from a semi-structured interview with 04 teachers working in two private schools of vocational education in the city of Natal / RN.
\end{abstract}

To reflect on the insights of teachers, authors such as Candau (2013), Pepper (2012), Moura (2007), Machado (2013), Vázquez (2011) and Araújo and Rodrigues (2011), helped to lead the discussion and analysis . It is possible to understand that the relationship between theory and practice is essential in developing a training for professional education. Their forms of articulation occur mainly by dichotomous visions and drive. Understanding teachers we might reveal that there is a prevalence of dichotomous view of theory and practice regarding the educational performance of professional technical training.

KEYWORDS: Relation theory and practice. Teachers. Professional education. 


\section{INTRODUÇÃO}

A educação profissional ao longo da história vem sendo marcada por perspectivas de formação que apresentam uma valorização dos saberes práticos, dimensão que é inerente a aprendizagem de uma profissão, mas que necessita estar integrada aos aspectos teóricos, políticos e sociais, para constituir-se em uma formação que entende o sujeito como um ser de pensamento e ação.

$\mathrm{Na}$ atual conjuntura da formação profissional a integração dos conhecimentos teóricos e práticos, propostas indissociáveis na formação dos sujeitos, é um desafio, que se constitui em um campo fértil de investigação e reflexão crítica voltada para a relação do pensar e fazer na compreensão da realidade educativa que tem como foco específico preparar os sujeitos para o exercício de uma profissão.

Nas discussões sobre a relação teoria prática, as compreensões e ações docente sobre o desenvolvimento do trabalho educativo, tornam-se aspectos importantes que ajuda a delinear como essa relação vem acontecendo no processo formativo, oportunizando um maior conhecimento das ações didático-pedagógicas dos professores que atuam na educação profissional.

Este artigo é um viés de uma pesquisa desenvolvida durante a disciplina de Formação docente para a educação profissional do Programa de Pós-Graduação em Educação Profissional (PPGEP) do Instituto Federal de Educação, Ciência e Tecnologia do Rio Grande do Norte (IFRN), que buscou investigar o percurso formativo, a percepção de trabalho e trabalho docente e, a relação teoria e prática de professores que atuam em escolas de educação profissional da rede privada de ensino da cidade de Natal/RN, tendo como sujeitos da pesquisa professores que atuam com disciplinas da área de formação geral e professores que atuam com disciplinas da área específica dos cursos técnicos dessas escolas ${ }^{1}$.

Na sistemática de análise e divulgação dos resultados da pesquisa, este artigo se voltou para a compreensão da relação teoria e prática no desenvolvimento do trabalho de professores de formação geral que atuam na educação profissional. Assim, buscamos na pesquisa qualitativa o respaldo para o desenvolvimento metodológico, que foi realizado a partir de uma entrevista semiestruturada com 04 professores que trabalham com disciplinas das áreas consideradas gerais de dois cursos técnicos em 02 escolas de educação profissional.

As escolas lócus de pesquisa são instituições da rede privada de ensino da cidade de Natal/RN, estão identificadas como IE1 e IE2, em cada escola foram entrevistados 02 professores. No IE1 os professores foram do Curso de Enfermagem, um com Licenciatura em Ciências Biológicas, e o outro formado em Licenciatura em Química. No IE2 os 02 professores entrevistados trabalham no Curso de Radiologia, um com Licenciatura em Física e outro com graduado em Ciências Biológicas.

Para melhor compreender a disposição das escolas, dos cursos e dos professores, os diálogos com os professores no momento da entrevista serão identificados de acordo com a lógica descrita na tabela 1, que no texto está disposto de acordo com a sigla da identificação geral.

\footnotetext{
${ }^{1}$ No contexto de um curso técnico de educação profissional, a área de formação geral corresponde a disciplinas como Português, Matemática, Química, Física, a área específica se refere às disciplinas diretamente ligadas à formação profissional do curso, por exemplo: em um curso de Radiologia tem disciplinas como Técnicas Radiológicas, Anatomia Radiológica, Assistência ao paciente em exames radiológicos.
} 
Quadro 1: Identificação dos espaços e sujeitos da pesquisa

\begin{tabular}{llll}
\hline Escolas & $\begin{array}{l}\text { Cursos } \\
\text { Técnicos }\end{array}$ & Professores - Identificação & $\begin{array}{l}\text { Identificação } \\
\text { Geral }\end{array}$ \\
\hline IE1 & Enfermagem & Licenciatura em Ciências Biológicas & PFG1.1 \\
& \multirow{3}{*}{ IE2 } & Licenciatura em Química & PFG1.2 \\
& Radiologia & $\begin{array}{l}\text { Licenciatura em Física } \\
\text { Graduação em Ciências Biológicas }\end{array}$ & PFG2.1 \\
& & PFG2.2 \\
\hline
\end{tabular}

Fonte: Elaboração própria

A partir da colaboração desses sujeitos, esta pesquisa buscou respostas para algumas inquietações que foram sendo refletidas ao longo da disciplina, no sentido de investigar sobre quais as percepções dos professores sobre a relação teoria e prática no processo ensino/aprendizagem? De que forma o currículo dos cursos que ofertam educação profissional expressam essa relação? E como é essa relação no cotidiano da educação profissional? Questões que na incompletude das discussões em sala de aula houve a necessidade de desenvolver uma investigação empírica, na qual proporcionou uma melhor compreensão da realidade educativa da educação profissional na rede privada de ensino, como também, possibilitou aos alunos da Pósgraduação em Educação Profissional, o exercício da pesquisa como princípio educativo no processo de formação acadêmica.

\section{TEORIA E PRÁTICA E SUA RELAÇÃO COM A FORMAÇÃO}

A teoria e a prática são dimensões basilares na formação humana integral ${ }^{2}$ dos sujeitos, a indissociabilidade dessas duas propostas consiste em um importante passo para que a formação profissional proporcione conhecimentos técnicos e teóricos, que junto com a análise crítica da realidade, desenvolvem a problematização das relações sociais, políticas e econômicas em que o sujeito trabalhador está inserido, preparando-o para além da ação do fazer profissional, como também uma maior compreensão e transformação das relações no mundo do trabalho.

O sentido da palavra teoria como ato de especular vem do pensamento platônico, de acordo com Garcia (1975, p. 119) [...] a partir de Platão, o sentido de teoria aparece muito associado a atividades de contemplação do espírito, de meditação, estudo, etc." Quanto a palavra prática, sua origem vem do grego práxis e "tem o sentido de agir, o fato de agir e, principalmente, a ação consciente, a ação inter-humana consciente". (CANDAU, 2013, p.58)

Nas contradições da sociedade em que vivemos a teoria e a prática estão implicadas com a valorização de determinadas atividades. Na sociedade capitalista há um privilégio do trabalho intelectual em detrimentos do trabalho manual, como consequência, algumas profissões que demandam os níveis de planejamento, organização e decisão ganham mais estatus social e melhor remuneração, daquelas profissões que se voltam para os aspectos do fazer laboral, que usam mais a força física para o trabalho. O que reforça a divisão de classes e suas respectivas profissões, em que a classe com mais aquisição financeira, tendem a assumir as profissões com demandas teóricas, e a classe popular, fica restrita as atividades profissionais relacionada ao fazer.

\footnotetext{
${ }^{2}$ Entendida de acordo com Moura (2013) como uma formação omnilateral ou politécnica, tendo como eixo estruturante o trabalho, a ciência, a tecnologia e a cultura. Disponível em: <http://www.scielo.br/pdf/ep/v39n3/10.pdf>. Acesso em: 22 jul. 2016
} 
A união das propostas teóricas e práticas na formação de profissionais não correspondem apenas aos aspectos metodológicos de aprendizagem, mais consiste em uma posição política que assume a finalidade educacional da formação humana integral, que se encontra subjacente na defesa de uma sociedade igualitária, de valorização dos que pensam e dos que fazem. Uma formação crítica, de análise da relação entre educação e sociedade e de evidências das propostas educativas dicotômicas, que estão a serviço da continuidade das divisões de classes sociais. Uma realidade de formação de sujeitos presentes na educação que requer atenção, pois como afirma Aranha (2006, p. 32) "a educação não pode ser compreendida fora de um contexto históricosocial concreto".

Alinhada a proposta da formação humana integral e a indissociabilidade entre teoria e prática, a práxis educacional se apresenta como uma atividade intencional que explicita os fins a serem atingidos no processo. As mediações pedagógicas baseadas na práxis desenvolvem nos sujeitos ações conscientes sobre a sua realidade de vida, envolvendo o pensar e o fazer dentro do contexto em que as relações sociais estão inseridas. Para Vázquez (2011, p. 241) a teoria "transforma nossa consciência dos fatos", e a prática como "ação efetiva sobre o mundo" tornam-se aspectos indissociáveis no processo de formação.

No entanto, as formas em que acontece a relação teoria e prática nem sempre estão a serviço de sua integração. Candau (2013) enfatiza que existem várias maneiras de compreender a relação em que a teoria e a prática se desenvolve, mas de modo geral, ela propõe que essa relação se faz por uma visão dicotômica e uma visão de unidade, nas quais dão forma há algumas concepções e ações educativas.

A visão dicotômica corresponde à separação entre teoria e prática, que em sua forma mais radical é entendida pela visão dissociativa, em que teoria e prática são perspectivas opostas, e em sua forma mais amena, a visão associativa, a teoria e prática são pólos separados, a prática é entendida como aplicação da teoria, o que concebe a teoria uma valorização científica submetendo a prática às suas premissas. (CANDAU, 2013)

A visão de unidade é compreendida na vinculação e integração entre teoria e prática, assim, a teoria depende da prática, que é a finalidade da teoria. Na definição dessa visão, Candau (2013) parte da compreensão de que é preciso à vivência dialética da teoria e da prática para ação do homem no mundo, a autora se inspira na práxis como elemento fundamental na formação humana, baseada nas discussões de Vázquez (2011).

A dissociação entre teoria e prática na formação dos profissionais da educação é um problema para o mundo do trabalho, porque vai proporcionar uma distância entre os conhecimentos adquiridos na formação dos alunos e aquilo que eles encontrarão em sua prática profissional. O professor como um mediador do processo educativo é um elemento importante para que as propostas de formação se efetivem. Entender a práxis como atividade teórico-prática no processo ensino/aprendizagem trata-se de um dos grandes desafios que enfrentam os profissionais da educação na atualidade.

Pimenta (2005, p.26) afirma que "o saber docente não é formado apenas da prática, sendo também nutrido pelas teorias da educação". Mediante esta afirmação, entendemos a teoria como papel fundamental e importante no processo ensino/aprendizagem, porém, de nada adianta apropriarmos de fundamentos teóricos, se não analisarmos os variados benefícios que o fazer profissional adquire neste processo, principalmente, quando auxilia na tomada de decisão, dentro de uma ação contextualizada, tornando possível o desenvolvimento dos saberes, compreendidos a partir dos diversos contextos da educação profissional. 
No processo da educação profissional a didática deve ser baseada na premissa de que todo ato educativo tem especificidade própria, e varia de acordo com as circunstâncias do contexto em que está inserida.

Ao se apropriar do conhecimento, o docente contribui com reflexões teóricas que proporcionam compreensões da aprendizagem, escolhendo, assim, as melhores formas de realizar o seu trabalho, sempre encontrando novas possibilidades para vencer os desafios e dificuldades, para desenvolver a sua atividade com segurança e qualidade.

Esta fundamentação fica clara quando verificamos o discurso de Pura (1989, p. 21), diferenciando didática teórica e prática:

\begin{abstract}
Didática teórica é aquela desenvolvida nos programas da disciplina, segundo pressupostos científicos que visam à ação educativa, mas distanciada desta. São pressupostos abstratos que se acumulam sobre o processo de ensino, na busca de tornálos mais eficientes. Didática prática é aquela vivenciada pelos professores nas escolas a partir do trabalho prático em sala de aula, dentro da organização escolar, em relação com as exigências sociais. Esta não tem por compromisso comprovar os elementos teóricos estudados em livros ou experimentados em laboratórios, mas tem em vista o aluno, seus interesses e necessidades práticas.
\end{abstract}

Nota-se, portanto, que o desafio fundamental para o profissional da educação é distinguir e compreender as teorias subentendidas na sua própria prática e originar condições para que, diante das teorias, se modifiquem pontos de vista, atitudes e posturas que influenciem a atuação em seu exercício educacional e profissional.

A experiência que observamos dentro da prática docente, possibilita entender e comentar que a perspectiva da formação continuada dos docentes, levando-os ao processo de melhoria das suas práticas pedagógicas, proporciona a quem atua com a formação de pessoas buscar formas que auxiliem o seu fazer pedagógico, principalmente, para os docentes da Educação Profissional, que em sua maioria são técnicos com conhecimentos específicos em sua área de atuação, não possuindo uma formação direcionada para a prática educacional. A partir desse contexto, fundamentamos a nossa fala de acordo com as ideias de Candau(2013), quando enfatiza a importância da formação do educador contextualizado com a prática, pois é esta que vai conduzindo o processo, uma arte a ser conquistada no fazer pedagógico.

\title{
2 METODOLOGIA
}

Diante do nosso objeto de estudo, a metodologia consistiu em uma abordagem qualitativa de pesquisa, por atender as análises e reflexões que são construídas nos discursos, subsidiando o pesquisador nas percepções, sentidos e significados das compreensões dos sujeitos pesquisados.

O caminho das reflexões se fez pelo procedimento da pesquisa de campo, contando com a pesquisa bibliográfica e a técnica da entrevista semi estruturada, para coleta de dados. $\mathrm{Na}$ pesquisa bibliográfica autores como Moura (2007) e Machado (2013) nos ajudaram nas discussões sobre a formação docente para educação profissional, Candau (2013) e Pimenta (2012) colaboraram para o entendimento das reflexões didáticas, Vázquez (2011) e Araújo e Rodrigues (2011) sistematizam a ideia da integração teoria e prática como práxis a ser perseguida na relação trabalho e educação.

A elaboração da entrevista semi estruturada aconteceu em sala de aula, com a participação de todos os alunos que cursavam a disciplina Formação docente para a educação profissional. As perguntas que orientaram a entrevista foram no sentido de compreender a 
relação teoria e prática na atuação docente, assim questionamos junto aos 4 professores colaboradores: Em sua percepção, como se dá a relação teoria e prática no processo de ensino e aprendizagem?Que experiências, você como docente, desenvolve com seus estudantes para permitir essa articulação entre teoria e prática?

\section{O CONTEXTO DA EDUCAÇÃO PROFISSIONAL NA FORMAÇÃO DOS PROFESSORES}

No entendimento da relação teoria e prática, a formação do professor é um aspecto importante a ser considerado quando se analisa as concepções dos sujeitos entrevistados. Os professores colaboradores desta pesquisa têm formação em nível superior, $01 \mathrm{com}$ bacharelado e 03 com licenciatura, destes um tem especialização e outro mestrado, fato que difere da realidade da formação docente para a educação profissional no Brasil, por serem professores que trabalham com disciplinas gerais dentro dos cursos técnicos de educação profissional. Machado (2013) vai afirmar que os professores da educação profissional são selecionados, principalmente, pela experiência profissional, não havendo uma preocupação efetiva com a formação pedagógica que é flexibilizada por programas de formação continuada, apresentando pouca efetividade na prática.

Moura (2007) indica que o trabalho docente na educação profissional requer uma formação que contemple a área de conhecimentos específicos, didático-político-pedagógicos e a especificidade da área da EPT, aspectos que contribuem para o desenvolvimento de uma prática contextualizada, compreendendo os interesses subjacentes, que induzem a uma reflexão sobre uma formação para que sociedade? E para que educação profissional e tecnológica? Conhecimentos e reflexões que podem ser melhores construídas em uma formação em nível superior.

Dos entrevistados percebemos uma situação favorável quanto à graduação em nível superior, a formação específica e a formação docente, os 04 professores entrevistados têm graduação, sendo 03 licenciados, 01 com bacharelado. Já em relação à educação profissional, a entrevista revela que a nenhum dos sujeitos entrevistados foi direcionada uma formação voltada para a área da EP, exemplo que podemos ver com o professor PFG2.1 ao apontar que na sua graduação se falava "[...] somente sobre o ensino médio, e alguma coisa sobre o ensino fundamental, profissionalizante não"

O silenciamento das discussões sobre EP é esperado nos bacharéis, mas deveria ser contemplada nas licenciaturas. A modalidade EP esta presente em todas as LDB (Lei de Diretrizes e Bases da Educação Nacional) promulgadas ao longo da segunda metade do século XX, na LDB no 4.024/61, como Ensino Técnico, e mais recente com a LDB no 9.394/96 como Educação Profissional e Tecnológica sendo uma modalidade de ensino na estrutura da educação brasileira.

A educação profissional requer um melhor direcionamento quanto à atuação de seus professores, visando desenvolver e integrar os conhecimentos teóricos e práticos, aspectos que historicamente foram dicotomizados em formações de vieses propedêutico e pragmático. 0 recorte realizado nesta investigação oportunizou uma compreensão de como os professores que atuam no ensino profissionalizante vêm entendendo a relação que a teoria e a prática assumem na EP.

Ao direcionarmos o nosso estudo à realidade da prática profissional do entrevistado PFG1.1, observamos que mesmo esse profissional possuindo mestrado, em seu processo formativo não houve discussão sobre a Educação Profissional. Atuando nesta área há mais de treze anos, a reflexão que desenvolveu foi construída na prática de ensino em cursos técnicos nas redes privadas de formação profissional. Situação comum aos demais professores, como aponta 
o entrevistado PFG2.1 ao relembrar que a formação da Licenciatura em Física "fala somente sobre o ensino médio, e alguma coisa sobre o ensino fundamental, profissionalizante não". 0 entrevistado PFG2.2 afirma que "nem na graduação nem na pós, nem nos cursos" aconteceu formação para EP, ressaltando que o mesmo tem graduação e trabalha a 03 anos na área.

O professor PFG1.2 foi o único que afirmou que houve em seu processo formativo uma formação na área da EP "Sim. Quando eu me formei em química pela Universidade Potiguar, foi naquele período que o governo pediu que até 2007 , se não me falhe a memória, todos os professores que estivessem em sala de aula eram para ter nível superior", explanação que está mais relacionada a aos desdobramentos da LDB no 9.394/96 em relação a obrigatoriedade da formação docente de modo geral, do que a especificidade de uma formação docente para EP.

\section{A RELAÇÃO TEORIA E PRÁTICA NO PROCESSO DE ENSINO E APRENDIZAGEM}

As compressões dos docentes sobre a relação teoria e prática dar indícios do panorama em que se encontra a educação profissional no Brasil, de acordo com Araújo e Rodrigues (2011), ao discutir as bases de uma didática para EP baseada em uma filosofia da práxis, aponta que existem dois principais projetos político-pedagógicos de disputa no terreno das práticas formativas, sendo

[...] um fundado nos ideais pragmáticos, que buscam subordinar a formação aos interesses estreitos e imediatos da realidade dada, e, outro, fundado na filosofia da práxis, que se compromete com a construção do homem pleno e vincula as ações formativas a um projeto de sociedade socialista. (ARAÚJO E RODRIGUES, 2011. p. 02)

$\mathrm{Na}$ realidade da formação de sujeitos para uma atividade produtiva encontramos estes ideais, que podem ser contemplados em sua totalidade, ou ainda conviverem simultaneamente expressados na realidade educacional como teorias e práticas pedagógicas em disputa nas escolas e nos centos de formação.

A realidade da prática docente em uma escola de formação profissional, pode ser expressada por meio das compreensões dos professores, assim as discussões apresentadas neste estudo, partiu da reflexão que indagou aos sujeitos entrevistados como se dar a relação teoria e prática no processo de ensino aprendizagem?

O entrevistado PFG1.1, atua no curso de Enfermagem, no qual podemos perceber uma preocupação com os riscos da área, que na relação teoria e prática deve ser considerada, pois o que está em jogo é a vida humana, para ele "há importância da teoria e da prática, de tirar todas as dúvidas porque na área da saúde qualquer erro é fatal". Acrescenta o cuidado em mostrar aos alunos a importância da disciplina que leciona (apesar da pergunta seguinte questionar se existem elementos na matriz curricular do curso em que atua que permitem a articulação entre teoria e prática, o entrevistado dá continuidade a de sua resposta da primeira pergunta).

\footnotetext{
Eu especifico muito, porque o aluno diz que essa disciplina não tem nada a ver, que não será visto na prática, e eu digo que vai sim. Na hora que você faz um bom resumo do paciente para o seu colega que vai lhe render no plantão, se não tiver digitado de uma forma clara, objetiva, você corre o risco do colega fazer alguma coisa errada. Na hora que você escreve bem no prontuário, então esse risco já é minimizado. (PFG1.1)
}

Essa resposta complementa seu entendimento prático sobre o que se aprende no curso e a utilidade na vida profissional, diante de sua fala pode-se compreender que a relação teoria prática se faz por uma visão dicotômica associativa como aponta Candau (2013, p. 61), pois é preciso "saber para prever, prever para prover", quando a disciplina não atende explicitamente a essa questão aplicacionista há um questionamento dos alunos diante do que é posto na matriz 
curricular, como aponta os professores PFG1.1, na citação acima, e o professor PFG2.1 quando diz que os alunos reclamam "pra que eu vou aprender tal disciplina que não tem nada a ver com minha prática".

Quando a pergunta sobre a relação teoria prática é direcionada ao entrevistado identificado como PFG1.2, obtivemos a seguinte resposta:

\begin{abstract}
A gente trabalha com a interdisciplinaridade. Trabalhamos também preparando os nossos alunos para o mercado lá fora, porque o aluno também pode atuar na rede privada, como pode ele vai prestar concurso na área da saúde. Então, eu trabalho com o meu aluno assim: situações do cotidiano. Por exemplo, eu trabalho muito situações como questões de provas de concurso da área da enfermagem, da nutrição. Então, a gente trabalha com aquele aluno para que ele esteja apto tanto na rede privada, como ele se sinta capacitado em buscar uma vaga de saúde em concursos públicos. (PFG1.2)
\end{abstract}

A compreensão da relação teoria e prática na fala do entrevistado acontece por meio da interdisciplinaridade, mas fica evidente em sua explanação que essa relação se volta para o mercado de trabalho, preparando o sujeito em um conhecimento teórico que o capacite para os possíveis espaços de trabalho, sejam públicos ou privados.

A disciplina que o professor leciona toma um viés propedêutico pelas discussões de questões para concursos, expressando uma flexibilidade que, por um lado, se apresenta como necessária, mas por outro, torna os sujeitos meros adaptados aos movimentos do mercado de trabalho capitalista, desenvolvendo competências ao espaço de trabalho que for mais favorável, neste caso o público ou privado.

$\mathrm{Na}$ atuação docente da educação profissional é preciso ir além dessa formação mercadológica de aspecto cognitivista, a relação teoria e prática deve ser pautada em situações que façam o aluno transitar do senso comum para o comportamento científico, do pensar e do fazer contextualizados com a realidade social.

O professor PFG1.2 é licenciado em Química, porém a disciplina em que atua é diferente da sua formação, pois trabalha com matemática nos cursos técnicos de Enfermagem e de Nutrição. O professor fala sobre sua formação inicial como um momento de articulação da teoria e prática

[...] a gente que trabalha nessa área de professor licenciatura, no mesmo momento que a gente tem que tá em sala de aula, assistindo aula, muitas vezes somos convidados para dar aula em escola e acaba que a opção termina sendo mais sugestiva aquela da sala de aula que a gente vai ministrar do que aonde a gente vai assistir aula." (PFG2.1)

Percebemos com estas colocações, que o tempo de formação inicial do entrevistado foi dividido com a experiência da docência. Atuando como professor desde 2002, a sua prática de sala de aula foi sendo construída por uma base dicotômica dissociativa da relação teoria e prática, em suas falas, fica entendido que a "ênfase é posta na total autonomia de um em relação ao outro" (CANDAU, 2013, p. 60), prática e teoria compreendidas separadamente.

O entrevistado PFG2.1, tem Licenciatura em Física e atua na Educação Profissional há 04 anos. Mesmo sendo sua formação em licenciatura, a educação profissional não foi abordada durante o curso. Na graduação ressalta a importância da participação no Programa de Bolsa de Iniciação à Docência (PIBID), para a sua formação enquanto professor, que the proporcionou uma melhor compreensão da teoria e da prática.

$\mathrm{Na}$ entrevista o professor, que trabalha no curso de Radiologia, compreende a relação teoria e prática como fundamental para o processo de ensino aprendizagem 
[...] você saber trabalhar a teoria que você recebeu e aí aliar a uma prática, isso aí é que vai é... nortear o aluno, que vai formar realmente o profissional, teoria de fato você ta lá sofrendo anotando e tal, mas quando você trabalha aquilo ali na prática é que você vai ver realmente qual vai ser esse profissional, e outro detalhe, eu falo muito que o profissional não é aquele que só tem teoria, tem que ter os dois, e outro detalhe, tem que saber o que ele está fazendo[...]. (PFG2.1)

O professor foi enfático explicando a importância dessa relação na formação do profissional, sua fala remete ao entendimento de uma visão de unidade como descreve Candau (2013), reafirmada na compreensão da disciplina que leciona

\footnotetext{
"uma das disciplinas que eu dou, envolvendo a física né, é a proteção radiológica[...], se o profissional não sabe se proteger contra a radiação, tem $\mathrm{N}$ efeitos da radiação, então se ele não sabe a proteção contra esses efeitos sua vida vai ser muito curta [...]". (PFG2.1)
}

O quarto sujeito da entrevista possui formação em Ciências Biológicas, o professor PFG2.2, trabalha na Educação Profissional há 03 anos. O mesmo informou que em sua formação acadêmica houve um pouco da relação teoria e prática, onde sua lembrança está voltada para a elaboração e execução de planos de aula, e lembrou também da disciplina Educação para o Ensino Especial, onde foi obrigado a elaborar e executar um projeto.

Quando questionado sobre a sua percepção da relação teoria e prática no processo ensino aprendizagem, transcrevemos abaixo a citação da entrevistada:

\begin{abstract}
Os alunos, pelo menos dessa parte, é o que mais gostam. Devido à curiosidade, muitos deles acham que a teoria não é importante e o que é importante é só a prática. 0 trabalho maior nosso, enquanto professor, é quando for para a prática ele perceber que aquilo que a gente deu em sala de aula pode tá sendo associado. Mas, sinceramente, eles adoram essa parte da prática; de você mostrar como faz cada um o que tem lá na sala de aula ter associação. Realmente eles gostam muito e é muito importante, porque aqui é que é o treino para lá fora eles estarem executando. (PFG2.2)
\end{abstract}

A descrição do professor de seu cotidiano expressa que a prática é entendida como aplicação da teoria, como treino, técnica a ser executada a partir das orientações do professor, mais uma vez encontramos a visão dicotômica associativa (CANDAU, 2013). Atuando nos módulos gerais do curso, em disciplinas como Anatomia Animal e Radiologia Veterinária, o professor afirma que trabalha artigos e a legislação, neste sentido vê que é competência também do técnico em radiologia atuar na parte animal. Então, há como fazer a associação "você fala de exames; de posicionamentos que no dia a dia o aluno trabalhando nessa parte vai encontrar." Continuou comentando:

\footnotetext{
Em outros cursos, como por exemplo, o de Análises Clínicas, a gente sempre leva os alunos para laboratórios. Exemplo na aula de Biologia Celular, a gente vai para um laboratório "ver/fazer" a diferença entre células animais e células vegetais e células de tecidos diferentes. Como por exemplo, o tecido sanguíneo e o tecido de revestimento da mucosa da boca. Então, aquela imagem que a gente tira do livro a gente encontra ela e vê ela no nosso organismo. Partindo daí, tem outras também na parte da análise que às vezes a gente faz: o exame de fezes; o exame parasitário.(PFG2.2)
}

Na busca de uma práxis educativa, a formação docente é um elemento fundamental para que ocorra uma ação efetiva de transformação das práticas pedagógicas, que deve ter a relação teoria e prática precisa, como base a visão de unidade. Para Candau $(2013$, p.68) "a teoria e a 
prática educativa, neste enfoque, são consideradas o núcleo articulador da formação do educador, na medida em que os dois pólos devem ser trabalhados simultaneamente, constituindo uma unidade indissolúvel", uma compreensão a ser perseguida na prática docente da educação profissional.

Como aponta as entrevistas, 03 dos professores expressaram em suas falas vivencias da relação teoria e prática em uma visão dicotômica, em suas formas dissociativa e associativa, tendo como finalidade às necessidades do mercado, pensamento ligado a uma formação que adapta os sujeitos aos interesses econômicos, de manutenção da sociedade capitalista. No entanto 01 professor apresentou uma visão que caminha para a compreensão de que a relação deve ser no sentido de unidade "saber alinhar teoria à prática" (PFG2,1), situação que o diferenciou de seus colegas, podendo estar relacionado a sua formação inicial que o oportunizou a experiência da docência enquanto alunos participante do PIBID, fato que, como vimos foi significativo em sua formação.

\section{A RELAÇÃO TEORIA E PRÁTICA NO COTIDIANO DA EDUCAÇÃO PROFISSIONAL}

No intuito de identificar e refletir se as práticas pedagógicas de sala de aula dos docentes entrevistados abarcam as dimensões teóricas e práticas de maneira integrada, realizamos a seguinte pergunta para aos quatro docentes entrevistados: Que experiências, você como docente, desenvolve com seus estudantes para permitir essa articulação entre teoria e prática?Com efeito, o professor PFG1.1 da instituição IE1, respondeu da seguinte maneira: "Eu trago textos da área da saúde para eles fazerem resumo né".Ao analisar a fala do docente, compreendemos que na sua percepção a relação teoria e prática se fundamenta numa perspectiva associativa, na qual a prática está à serviço da teoria.

A esse respeito, as autoras Candau (2013, p. 60) apresentam:

\footnotetext{
Na visão associativa, teoria e prática são pólos separados, mas não opostos. Na verdade, estão justapostos. O primado é da teoria. A prática deve ser uma aplicação da teoria. $A$ prática propriamente não inventa, não cria, não introduz situações novas. A inovação vem sempre da teoria. A prática adquirirá relevância na medida em que for fiel aos parâmetros da teoria [...]
}

Diferentemente da visão associativa, a visão de unidade propõe uma união indissociável entre teoria e prática. Para tanto, mesmo sendo dimensões distintas, ambas formam uma relação de dependência que permite ao professor refletir e investigar a sua prática constantemente.

Pimenta (2012, p. 05) aponta que o saber docente não é formado apenas da prática, sendo também nutrido pelas teorias da educação. Dessa forma, "a teoria tem importância fundamental na formação de docentes, pois dota os sujeitos de valores e pontos de vista para uma ação contextualizada [...]"

Nesse contexto, observamos que a reflexão sobre a ação deve fazer parte do processo de ensino. Atualmente vislumbramos a ampliação de debates que nos permitem pensar a Educação Profissional, sendo capaz de fornecer conhecimentos que, além de técnicos instrumentais, compreendam uma dimensão dialética e humanística, que seja pautada em valores sociais, culturais,almejando a formação integral de sujeitos que pensam, refletem e buscam criticamente a transformação do seu meio social.

Com efeito, o professor PFG1.2 relatou: "Justo! Diluição, concentração de solução, essa parte de medicamentos, trazendo a matemática para a prática. Pois, a prática eles vão trabalhar com a manipulação dos medicamentos". Assim como o PFG1.1, o PFG1.2 relatam que 
estabelecem relação teoria e prática no decorrer de suas aulas. Porém identificamos que essa articulação do PFG1.2 também se dá sob a ótica de associação explicitada anteriormente.

Além das entrevistas realizadas no IE1 contamos com a instituição IE2, onde dois docentes de formação geral foram entrevistados. No tocante às experiências com a prática de sala de aula desses docentes de formação geral o PFG2.1 discorreu:

\begin{abstract}
Eu tento trabalhar o dia a dia do... do aluno, o dia dele como profissional né, embora eu não trabalhar na área diretamente de radiologia, mas tenho conhecimento, tenho amigos que trabalham nessa área e devido à experiência dessas pessoas consigo trazer né, é experiências pra sala de aula através de conversas, e vejo o dia a dia do aluno pra trabalhar esse dia a dia dele como seria é... a sua prática, ou como é as visitas que eles fazem, eu tento trabalhar esse lado e mostrar, até mesmo quando eles vão ao médico, quando vão fazer um raio $x$, etc., então eu pego aquele momento dele e tento ver será que o técnico fez isso? Tá correto? Será que não seria melhor fazer dessa maneira? Então eu tento trabalhar dessa maneira pra... é... ter uma visão mais ampla aí de... da... teoria com a prática.
\end{abstract}

Um aspecto merecedor de destaque na fala do PFG2.1 é que o mesmo busca durante as aulas atrelar as experiências dos alunos com o conteúdo trabalhado em sala de aula. Essa articulação permite tornar o processo de ensino aprendizagem mais dinâmico e significativo. Destacamos a importância de trazer para a realidade da escola, o contexto social do aluno, o que apresenta uma iniciativa mais próxima da visão de unidade proposta por Candau (2013) de trabalhar a relação teoria e prática de simultaneidade e reciprocidade. Esse entendimento nos ajuda a compreender o currículo como possibilidade de articular saberes e experiências dos sujeitos de aprendizagens.

Segundo Sacristán (1998, p. 43),

[...] O currículo concebido como experiências de aprendizagem que os alunos recebem é garantir a continuidade dos mesmos e definir uma linha de progresso ordenado para o saber sistematizado, que continua necessário; algo que está bastante obstaculizado por uma instituição que proporciona saberes entrecortados e justapostos arbitrariamente.

Identifica-se que a relação teoria e prática expressada na fala do professor quando faz a relação com as experiências dos alunos contribui para a construção de um saber mais sistematizado, que na expressão da fala do professor PFG2.1 é mediado pelo discurso, nos exemplos do cotidiano, uma forma de integração abstrata da relação teoria e prática.

Compreendendo que essa relação acontece também de outras maneiras, o entrevistador instiga a reflexão de como essa relação pode ser construída, além do discurso. Na inquietação o entrevistador propõe: "[...] eu fiquei curiosa, que essa articulação é... querendo ou não, ao meu ver ainda fica no discurso entendeu? Eu digo a ação de pegar e fazer aquilo, se você faz". O professor entrevistado aponta que em

[...] algumas aulas dá pra trazer materiais mesmo, ampola, é... capote, etc. pra gente trabalhar, fazer em sala mesmo, sei lá, tipo um teatrozinho lá de como é que é a sala de raio x e trabalhar, dá pra fazer isso aí, depende muito de cada conteúdo, tem conteúdo que é só teoria que não dá pra trabalhar, tem outros que é prática. (PFG2.1)

Fica, pois, evidente, na fala do professor que a relação teoria e prática além de se apresentar no âmbito do discurso, também se insere na visão dicotômica de separação, com destaque para o seguinte trecho "tem conteúdo que é só teoria que não dá pra trabalhar, tem outros que é prática". (PFG2.1). Na entrevista com esse professor pode-se perceber que 
inicialmente, ele apresentou em sua fala uma prática que caminha para uma visão de unidade, mas logo expõe aspectos da visão dicotômica, compartilhada pelos demais entrevistados.

A entrevista com o docente PFG2.2, confirma a tendência da visão dicotômica da relação teoria e prática presente na sua experiência profissional, expressando relatos de outros momentos de trabalho. O professor fez o seguinte questionamento: "[...] Posso falar em outro curso ou só na radiologia?", na resposta afirmativa do entrevistador, o professor continuou

[...] em outros cursos como por exemplo o de análises a gente sempre leva os alunos para laboratórios. Já sexta-feira agora eu tô dando aula de biologia celular e a gente vai para um laboratório ver/fazer a diferença entre células animais e células vegetais e células de tecidos diferentes, como por exemplo do tecido sanguíneo e do tecido de revestimento da mucosa da boca. Então, aquela imagem que a gente tira do livro a gente encontra ela e vê ela no nosso organismo. Partindo daí, tem outras também na parte da análise que às vezes a gente faz: o exame de fezes; o exame parasitário. (PFG2.2)

Percebe-se que a prática em laboratório exercida por esse professor expressa uma visão dicotômica com a teoria, ele deixa a entender que o conteúdo foi trabalhado em sala de aula "aquela imagem do livro que a gente encontra" e usa as aulas para afirmar o que o livro apresenta, uma indicação da teoria como verdade e da prática como prova da teoria apresentada no livro caminha na direção de mais integração da relação teoria e prática.

Nas entrevistas realizadas foi evidenciado que os professores compreendem a relação teoria e prática de forma dicotômica, apenas um desses professores apresentou uma tendência à visão de unidade, em sua entrevista foi possível perceber as duas propostas em momentos de suas aulas. Outro aspecto importante diz respeito às formas metodológicas dessa relação, pois percebemos que ela acontece no plano do discurso e no plano da prática, mas uma prática representacional da realidade, um ensaio da realidade. Outra forma metodológica dessa relação se faz na inserção dos sujeitos na realidade profissional, que acontece nos cursos de formação profissional no momento dos estágios, mas que não foi apresentado por nenhum dos entrevistados.

Outro fato relevante é que todos os professores apresentam formação em nível superior, 03 com licenciatura, um bacharelado, e um com pós-graduação em mestrado, o que difere da tendência histórica dos professores que atuam na EP na rede privada de ensino, apresentarem apenas a experiência como necessária a atuar na área. Fato que pode ser compreendido em uma dimensão micro, por esses professores serem das disciplinas específicas, e em uma compreensão macro pela expansão da oferta de graduação nos últimos anos.

A importância da relação teoria prática foi expressada por todos os professores durante a entrevista, apesar de ainda a compreenderem por uma visão dicotômica. $O$ fato desses professores trabalharem no contexto da rede privada da EP molda suas compreensões em relação à finalidade educativa. A perspectiva mercadológica de preparar o profissional para o mercado foi presente nos discursos dos professores. O que expressa à necessidade de uma formação voltada para a área da EP que tenha uma visão crítica e problematizadora das relações econômicas no mundo capitalista, que faça os sujeitos entenderem que é preciso centralizar o ser humano e não a lucratividade nas relações que envolve educação e trabalho, trabalho e mundo do trabalho.

\section{CONSIDERAÇÕES FINAIS}


Realizar esse estudo de pesquisa por meio de entrevistas com professores de formação geral da Educação Profissional, executadas em duas instituições que atuam com este tipo deformação profissional em Natal/ RN nos permitiu enxergar que existe um certo distanciamento entre a formação acadêmica dos professores e a aplicação dos saberes direcionados à educação profissional, principalmente, quando abordou-se questionamentos com os entrevistados, que compreendessem os entendimentos necessários que os professores deveriam ter da relação teoria e prática no desenvolvimento do seu fazer pedagógico.

Percebe-se, portanto, que não existe na formação de professores, sínteses de um perfil ideal que trabalhe ensinamentos docentes para a Educação Profissional, o que tem favorecido que o profissional que atua nesta área, em sua grande maioria, assuma uma sala de aula sem possuir os conhecimentos específicos da educação, mas possuindo saberes específicos e técnicos da ocupação para atuar em determinadas áreas. Porém, em nossos estudos, percebemos que o ideal seria que o professor da EP, necessariamente, tivesse conhecimentos intelectuais que 0 possibilitassem problematizar e mediar o processo de ensino aprendizagem, favorecendo para que os discentes se tornem indivíduos com conhecimentos na ciência, na técnica, na tecnologia, na cultura, pautados no compromisso com a ética humana.

Nesse sentido, é necessária a existência de uma formação docente no âmbito do ensino superior, que articule eixos envolvendo conhecimentos basilares, seu desenvolvimento seja direcionado à área da educação profissional, caminhando para a práxis pedagógica, proposta a partir da análise crítica da realidade, das teorias e práticas que contribuam para uma formação de qualidade, entendendo os sujeitos na sua condição humana de profissionais pensantes, que articulem conhecimentos, habilidades e valores, permitindo o desenvolvimento contínuo em sua ação transformadora.

\section{REFERÊNCIAS BIBLIOGRÁFICAS}

1. BRASIL. Lei № 9.394, de 20 de dezembro de 1996. Estabelece as diretrizes e bases da educação nacional. Diário Oficial da União, Brasília, DF, 20 dez. 1996. Disponível em:<http://www2.camara.leg.br/legin/fed/lei/1996/lei-9394-20-dezembro-1996-362578 publica caooriginal-1-pl.html>. Acesso em: 05 jan. 2016.

2. CANDAU. Vera Maria (Org.). Rumo a uma nova didática. Petrópolis: Vozes, 2013.

3. MACHADO, Lucília Regina de Souza. Formação de Professores para a Educação Profissional Tecnológica: perspectivas históricas e desafios contemporâneos. In: MOURA, Dante Henrique (Org.) Produção de conhecimento, políticas públicas e formação docente em educação profissional. Campinas, SP: Mercado das Letras, 2013.

4. MOURA, Dante Henrique. A formação de docentes para uma educação profissional e tecnológica socialmente produtiva. Disponível em: http://www.anpae.org.br/congressos_ antigos/simposio2007/106.pdf. Acesso em: 15 mar 2016.

5. PIMENTA, Selma Garrido (Org.). Saberes Pedagógicos e atividade docente. 8. ed. São Paulo: Cortez, 2012.

6. PURA, Lucia Oliver M. Didática Teórica e Didática Prática. São Paulo: Loyola, 2000. 
7. SACRISTÁN, J. Gimeno. O Currículo: uma reflexão sobre a prática. Porto Alegre: Artmed. 1998. 